\title{
Desastres e oficinas para preparo dos profissionais da saúde em Petrópolis - Rio Janeiro
}

\author{
Disaster and workshops for preparing healthcare \\ professionals in Petrópolis - Rio de Janeiro \\ Desastres y talleres para la preparación de \\ profesionales de salud en Petrópolis - Rio de Janeiro
}

Luiz Henrique de Sá ${ }^{1}$ Samira Younes Ibrahim ${ }^{2}$

\section{Resumo}

SÁ, H. de L.; IBRAHIM, Y. S. Desastres e oficinas para preparo dos profissionais da saúde em Petrópolis - Rio Janeiro. Rev. C\&Trópico, v. 45, n. 2, p. 187-208, 2021. DOI: https:// doi.org/10.33148/cetropicov45n2(2021)art12

Quando ocorrem desastres, os profissionais da saúde são convocados para o trabalho de emergência. É frequente o modelo de treinamento em que os servidores recebem orientações e determinações sem possibilidade de diálogo e de soluções conjuntas. Por isso, com uma abordagem diferenciada, foram realizadas oficinas com profissionais da atenção básica do Município de Petrópolis, estado do Rio de Janeiro, Brasil. Essa localidade foi uma das mais afetadas pelo desastre da Região Serrana em janeiro de 2011. Neste relato de experiência, destacam-se o diálogo e a vivência anterior dos participantes que estiveram em situações de desastres, evidenciando o sofrimento social pelo qual eles passaram e a importância da prática do acolhimento. A dimensão emocional foi reconhecida como a mais vulnerável. A prevenção, a solidariedade e a intersetorialidade foram acentuadas como inexistentes. Salienta-se a necessidade de união e de compromisso entre os poderes, municipal, estadual e federal, para que ocorra a recuperação social. Os resultados trazem aspectos norteadores revelando que se fazem necessárias uma atualização das políticas públicas em desastres e a oferta de orientações com relação ao cuidado integral.

Palavras-chave: Desastres. Diálogo. Aprendizagem. Órgãos Públicos. Atenção Primária à Saúde.

1 Gerente da Atenção Primária, Petrópolis, RJ. Representante de Petrópolis no VIGIdesastres (MS). Membro da Rede de Cuidados, RJ. E-mail: henrikisa@gmail.com. Orcid: https://orcid.org/000-0002-4031-2426

2 Doutoranda Piscossociologia de Comunidades e Ecologia Social (EICOS/UFRJ). Membro da Rede de Cuidados, RJ. E-mail: samirayounes@gmail.com. Orcid: https://orcid.org/0000-0002-6828-7672 


\section{Abstract}

SÁ, H. de L.; IBRAHIM, Y. S. Disaster and workshops for preparing healthcare professionals in Petrópolis - Rio de Janeiro. Rev. CઐTrópico, v. 45, n. 2, p. 187-208, 2021. DOI: https://doi.org/10.33148/cetropicov45n2(2021)art12

In disasters, health professionals are called to work. It's common the use of a training model in which health agents receive orientation and commands without the possibility of dialogue and joint solutions. With a different approach, workshops were held with primary health care in the municipality of Petrópolis, State of Rio de Janeiro, Brazil. This city was among the most affected by the highland region disaster in January of 2011. In this experience report, the dialogue and the previous experience of participants in disaster situations were highlighted, where they emphasized the social suffering and the importance of a welcoming practice. The emotional aspect has been recognized as the most vulnerable. Prevention, solidarity and intersectoriality were acknowledged as non-existent. There is a necessity of union and commitment between the city, state and federal powers for social recovery to take place. The results are guidelines for the updating of public policies on disasters and for the creation of integral care.

Keywords: Disasters. Dialogue. Learning. Public Agencies.Primary Health Care.

\section{Resumen}

SÁ, H. de L.; IBRAHIM, Y. Desastres y talleres para la preparación de profesionales de salud en Petrópolis - Rio de Janeiro. Rev. CઐTrópico, v. 45, n. 2, p. 187-208, 2021. DOI: https://doi.org/10.33148/cetropicov45n2(2021)art12

Cuando ocurren desastres, los profesionales de salud son llamados a trabajar en emergencias. Es frecuente el modelo de entrenamiento en el que los empleados reciben orientación y determinaciones sin la posibilidad de diálogo y de soluciones conjuntas. Por ello, con un abordaje diferenciado, se realizaron talleres con profesionales de la atención primaria del municipio de Petrópolis, en la provincia de Rio de Janeiro, Brasil, uno de los más afectados por el desastre que ocurrió en la región de la sierra, en enero de 2011. En ese relato de experiencia, se destaca el diálogo y la experiencia previa de los participantes que han estado en situaciones de desastre, haciendo evidencia al sufrimiento social por el que pasaron y la importancia de la práctica del acogimiento. La dimensión emocional fue reconocida como la más vulnerable. Se destacó como inexistente la prevención, la solidaridad y la intersectorialidad. Se pone de relieve la necesidad de unión y compromiso entre los poderes, municipales, estatales y federales, para que la recuperación social se produzca. Los resultados aportan aspectos orientadores, revelando que es necesaria la actualización de las políticas públicas en desastres y el aporte de orientaciones relacionadas al cuidado integral.

Palabras Clave: Desastres. Diálogo. Aprendizaje. Organismos Públicos. Atención Primaria en Salud. 


\section{Introdução}

No mundo globalizado, a rapidez nas comunicações, a homogeneização dos costumes e das ofertas e a pasteurização das imagens no dia a dia nos pode fazer esquecer que diversos países têm suas peculiaridades e, entre elas,vem a competência em responder a determinados eventos.

No Brasil, a capacidade instalada para lidar com situações de desastres encontra-se em construção, principalmente depois da catastrofe da Região Serrana do Estado do Rio de Janeiro, em janeiro de 2011. De lá para cá, foram criados órgãos nas três esferas governamentais (federal, estadual e municipal) com a finalidade de preparar contingentes para atuar em todas as etapas dos desastres. Nesse sentido, o Governo Federal implantou, em 2011, o Centro Nacional de Monitoramento e Alerta de Desastres Naturais (CEMADEN) ${ }^{3}$ e a Força Tarefa de Apoio Técnico e Emergência ${ }^{4}$, além disso, foi sancionada, em abril de 2012, a Lei n. $12.608^{5}$, que estabeleceu a Política Nacional de Proteção e Defesa Civil.

Já é possível sentir uma melhora nos atendimentos a desasatres depois dessas ações, porém, a grande maioria dos municípios ainda não conta com Secretarias de Defesa Civil e nem com Quartéis de Bombeiros, o que acaba por demandar a profissionais da área da saúde um engajamento e uma atuação que ficam, muitas vezes, além de sua capacidade, seja de conhecimento ou de preparo efetivo para atuar em desastres.

O Município de Petrópolis sempre sofreu com as chuvas, desde o tempo do Império, quando a corte passava os verões na cidade. Quem é filho do lugar acostumou-se, desde pequeno, com as "enchentes". Tudo se resumia a deixar a água abaixar, depois lavar e limpar. Os bombeiros foram os heróis que tentavam salvar as pessoas que foram mais atingidas. Assim, a naturalização dos desastres foi criada na mente dos petropolitanos, o que é um engodo, contribuindo para que as populações assimilem uma versão oficial e deturpada do que é um desastre. Imagina-se que, de forma semelhante, o mesmo ocorreu em outros municípios.

A catástrofe de 2011 na Região Serrana do Estado do Rio de Janeiro, Brasil, colocou em evidência a urgência em modificar a legislação e a forma de pensar, de elaborar e de atuar em situações de desastres. O conceito de prevenção, até então precário, começou a ser utilizado como uma das etapas para se lidar com esses desastres. Órgãos foram criados, salas de situação foram montadas em vários níveis governamentais, Planos de Contingência ganharam visibilidade e importância, secretarias de governo foram criadas, verbas foram destinadas e o país vem tentando suprir a ausência de infraestrutura para o enfrentamento dessas situações. Caminhamos já algum trajeto, porém muito ainda necessita ser feito, embora Petrópolis hoje se encontre muito mais preparada para os desastres.

3 Para mais informaçãoes, acessar: http://www.cemaden.gov.br/.

4 Para mais informações, acessar: https://pt.wikipedia.org/wiki/For\%C3\%A7a_Nacional_de_Apoio_T\%C3\%A9cnico_de_Emerg\%C3\%AAncia.

5 Para mais informações, acessar: http://www.planalto.gov.br/ccivil_03/_Ato2011-2014/2012/Lei/L12608. htm. 
Na Secretaria de Saúde do Município, os profissionais vêm passando por variados treinamentos já há alguns anos. Hoje, eles se encontram informados e atualizados sobre como agir no atendimento à população nesses momentos de dor e de perdas. O que se percebeu ao longo do tempo é que existe a necessidade de criar ações conjuntas para que o trabalho seja compartilhado. A população, os profissionais que estão trabalhando em campo e os órgãos governamentais precisam estabelecer relações dialógicas e de troca entre si. Com esse propósito, foram realizadas oficinas com os profissionais de saúde com o intuito de ouvi-los em suas percepções sobre os acontecimentos, suas ideias de como atuar e suas avaliações daquilo que vivenciaram ao longo de suas histórias. Utilizouse a obra Inundações e Cuidado Integral: guia para discussões técnicas e comunitárias, de Valencio, Ibrahim e Gonçalves (2018) como base para as oficinas e foram realizadas considerações sobre os dados apurados. Esse tipo de trabalho apresenta a possibilidade de ser repetido em outros municípios, oferecendo informações capazes de auxiliar nos processos de gerenciamento e na programação de ações em determinado território.

\section{O município de Petrópolis}

A história de Petrópolis registra que a cidade já foi o habitat dos índios colorados e posteriormente foi o local da colonização portuguesa. A primeira anotação de cessão de terras (Sesmarias) na região data de 1686. Sesmaria era um mecanismo administrativo utilizado pelo rei de Portugal, que favorecia uma pessoa com a doação de um lote de terra virgem, procedimento utilizado na época colonial brasileira (BRASIL ESCOLA, 2019). A fundação de Petrópolis ocorreu em 1843 pelo Imperador Dom Pedro II (PETRÓPOLIS, 2019).

O Município de Petrópolis faz parte da Região Serrana do Estado do Rio de Janeiro, Sudeste do Brasil. Corresponde a 11,5\% da Região Serrana e a 1,8\% da extensão do Estado do Rio de Janeiro. A localidade está situada no alto da Serra da Estrela, a 810 metros acima do nível do mar, com cerca de 850 metros de altitude, e pertence ao complexo do Parque Nacional da Serra dos Órgãos. Suas coordenadas geográficas são: 22030'18” de latitude Sul e 4310'44' de longitude Oeste (PETRÓPOLIS, 2014, p. 5154). Pelo Decreto n. 87.561, de 12 de setembro de 1982, foi criada no município a Área de Proteção Ambiental (APA) de Petrópolis, com 68.395 ha, que faz parte da Reserva da Biosfera da Mata Atlântica (RBMA) (BRASIL, 2007, p. 27).

A estrutura geológica do município favorece os movimentos de massa, com destaque para os escorregamentos e, consequentemente, recomenda-se atenção para o desmatamento, para as formas de ocupação do solo e para a agricultura (PETRÓPOLIS, 2014, p. 477-481). Porém, o crescimento populacional, a inexistência de soluções seguras para a falta de moradia, os movimentos de massa, as inundações bruscas, entre outros, expõem os munícipes ao aumento considerável dos riscos de desastres.

Inundações têm destaque na região, em especial nos anos de 1930, 1945, 1947, 1966, 1988 e 2011 (PETRÓPOLIS, 2018, p. 572). Entre 1991 e 2010, o município registrou seis inundações bruscas e 17 movimentos de massa (BRASIL, 2012a). 
Um dos mais graves desastres ocorreu entre o dia 11 e a madrugada do dia 12 janeiro de 2011, causando diversos danos. O Anuário Brasileiro de Desastres Naturais 2011 apresenta da seguinte forma a tragédia da Região Serrana Fluminense:

"O Megadesastre 11da Região Serrana do Rio de Janeiro" ocorreu entre a noite do dia 11 e a manhã do dia 12 deJaneiro de 2011. Deixando um número incalculável de cicatrizes de escorregamentos em encostas de quatro municípios - Nova Friburgo, Teresópolis, Petrópolis e Sumidouro -, principalmente nas duas primeiras, e provocando prejuízos indiretos por conta de enxurradas em mais três municípios - Areal, São José do Vale do Rio Preto e Bom Jardim. O "Megadesastre" provocou 912 mortes e deixou mais de 45.000 desabrigados e desalojados, caracterizando-se como o maior desastre registrado no Brasil e consolidando, infelizmente, a Serra Fluminense como a região brasileira com o maior quantitativo de vítimas fatais provocadas por desastres naturais (40\% do total nacional entre 1988 e 2012). (BRASIL, 2012a, p. 63)

Esse desastre foi um marco no cenário brasileiro, modificando o entendimento e os procedimentos de ação e, como evidenciado anteriormente, isso motivou a formulação da Lei n. 12.608, da Secretaria Nacional de Proteção e Defesa Civil (SNPDC, 2012b).

Assim, como resultado de amadurecimento após vivência de vários desastres e dando ênfase à prevenção, em maio de 2018, a Câmara Municipal do Município de Petrópolis sancionou a Lei n. 7.654/2018 (PETRÓPOLIS, 2018a), que gerou a Política Municipal dos Princípios da Proteção e Defesa Civil e a Educação Ambiental, de forma integrada aos conteúdos obrigatórios dos currículos da rede municipal de ensino, criando o projeto Defesa Civil nas Escolas. Essa lei tem como objetivo a criação de ações de conscientização para redução de riscos de desastres, com atividades voltadas para professores e alunos (PETRÓPOLIS, 2018b), e, como proposta, abranger toda a rede composta de 182 unidades de ensino e 42 mil alunos, pois sabe-se que eles são potentes multiplicadores em suas respectivas famílias e comunidades.

\section{A demanda e os objetivos}

Diante do histórico do Município de Petrópolis com desastres, é comum que a trajetória dos servidores municipais seja permeada por esses acontecimentos. É habitual que tais servidores ocupem dois papéis simultaneamente: como profissionais e como sobreviventes. Em ambos os papéis, eles estão diante de situações extremas, que exigem rapidez nas intervenções e encaminhamentos eficientes. Nota-se, portanto, que há a necessidade de formação e de atualizações contínuas dos funcionários públicos.

Uma preocupação que apresenta relevância internacional foi a que a Organização Pan-Americana da Saúde (OPAS, 2002) sistematizou: a Opas sugeriu 
propostas sobre as Funções Essenciais da Saúde Pública e, entre elas, a Redução do Impacto das Emergências e Desastres em Saúde aparece como a $11^{\text {a }}$ proposição. Das ações apresentadas, destacam-se estas três orientações:

O desenvolvimento de políticas, o planejamento e a realização de ações de prevenção, mitigação, preparação, resposta e reabilitação para reduzir o impacto dos desastres sobre a saúde pública; um enfoque integral com relação aos danos e à origem de todas ou de cada uma das emergências ou desastres possíveis na realidade do país; e a participação de todo o sistema de saúde e a mais ampla colaboração intersetorial e interinstitucional na redução do impacto de emergências e desastres. (OPAS, 2002)

No Brasil, tais orientações se mantêm presentes e atualizadas , Organização Mundial da Saúde (OMS) e pelo Ministério da Saúde (MS), que recebem reforço com a recomendação de fortalecer a capacidade de respostas da área da saúde,assim como para aprimorar a capacitação dos profissionais para as intervenções durante e após os desastres (OPAS; MS, 2015; OPAS, 2010a; 2010b).

Para as oficinas realizadas em 2018, buscou-se como instrumento o diálogo e a escolha pela construção de soluções conjuntas. Uma alternativa diferente dos exemplos que foram relatados sobre relações assimétricas, baseadas no autoritarismo e em posturas desrespeitosas em relação à cidadania e à violação de direitos humanos.

Ao longo dos últimos dez anos acompanhando os acontecimentos relacionados a desastres, é possível afirmar o dever que se tem de facilitar e de incrementar o diálogo entre os diversos atores nesses momentos. É necessário que os sobreviventes, os técnicos e os representantes dos órgãos oficiais e de Organizações não Governamentais (ONGs) possam estabelecer uma relação simétrica durante o desenvolvimento dos trabalhos, sejam eles de prevenção, de resposta ou de reconstrução. Compartilha-se da premissa de que os resultados das ações e as decisões psicossociais realizadas nas primeiras 72 horas do desastre se refletem nas semanas seguintes e que realizar essas ações deveria ser de responsabilidade das autoridades governamentais (OPAS, 2010a, p. 8).

Acredita-se que um dos desafios de trabalhar com desastres é a efetivação do desenvolvimento de ações intersetoriais. Entende-se que o diálogo é a base que gera a possibilidade de uma escuta qualificada para a construção de ações conjuntas. Nesse sentido, o diálogo é uma referência que se alinha com os princípios e os valores da Agenda de Saúde Sustentável para as Américas 2018-2030 (ASSA). Na agenda, o tema desastre está presente como objetivo 8: "Fortalecer as capacidades nacionais e regionais de preparação, prevenção, detecção, vigilância e resposta a surtos de doenças e às emergências e desastres que afetam a saúde da população" (OPAS; OMS, 2017, p. 31); e as metas para as Américas foram estabelecidas até o ano de 2030 (OPAS; OMS, 2017, p. 39). A educação continuada de profissionais para lidar com desastres faz parte do preparo do setor saúde. 
As oficinas tiveram como foco, justamente, o incremento do diálogo como forma de condução do ofício profissional de maneira mais humanizada, cuja relação pudesse contribuir para o enriquecimento de ambas as partes. Com essas Oficinas, pretendeu-se também clarificar quais interpretações o profissional de saúde da rede municipal tem em relação à experiência de vivenciar situações de desastres, como atuar nessas condições e qual avaliação ele faz dos órgãos envolvidos. Assim, o trabalho teve o intuito de colaborar para que se tenha um quadro mais claro do que os profissionais da saúde pensam e sentem em relação aos desastres e da forma como tem sido realizado o trabalho nessas situações.

\section{O Sistema Único de Saúde (SUS) e as Oficinas}

O Brasil conta com o Sistema Único de Saúde (SUS) ${ }^{6}$, que tem como base a universalidade, a integralidade e a equanimidade, o que garante saúde aos cidadãos sem distinção, de forma completa, e atendendo a cada um em suas necessidades. O SUS é formado por três instâncias: a atenção primária, a secundária com suas especialidades e a terciária.

Dentro do SUS, a Atenção Primária,ou Atenção Básica (AB) como também é conhecida, é formada por unidades básicas que se diferenciam daquelas que prestam atendimento à população em termos de demanda espontânea. As unidades de Atenção Básica (AB) fazem parte da Estratégia da Saúde da Família (ESF), que acompanha os usuários cadastrados dentro de determinado território, localizado em bairros e em distritos dos municípios (MARQUI et al., 2010).

A Atenção Básica é preferencialmente a porta de entrada para as redes de saúde do município, possui papel fundamental em todas as etapas (prevenção, mitigação, resposta, reconstrução) que envolvem desastres, por causa do conhecimento que detém sobre o seu território de ação, em especial, aquele saber dos Agentes Comunitários de Saúde (ACS).

A profissão de ACS é de fundamental importância para o desenvolvimento da Estratégia da Saúde da Família. As atribuições designadas ao ACS estão dispostas na Portaria GM/MS n. 1.886, de 18 de dezembro de 1997 (BRASIL, 1997), e no Decreto Federal n. 3.189, de 4 de outubro de 1999 (BRASIL, 1999). Nessas legislações estão estabelecidas as diretrizes para o exercício das atividades de ACS, possibilitando uma proposição qualitativa de suas ações e evidenciando um perfil profissional que concentra atividades na promoção da saúde, seja pela prevenção de doenças, seja pela mobilização de recursos e práticas sociais de promoção da vida e cidadania ou mesmo pela orientação de indivíduos, grupos e populações, com características de educação popular em saúde e acompanhamento de famílias.

Além disso, desdobramentos das situações de desastres podem surgir, tanto individual quanto coletivamente, ao longo do tempo, e, como os profissionais da Atenção Básica acompanham de forma contínua a saúde dos moradores, eles podem ser os primeiros a identificar o surgimento de novas necessidades no cuidado integral. Para Oliveira e Pompeu (2015, p. 8), os familiares que sobrevivem a um desastre estão em situação de

6 Para mais informações, acesse: www.saude.gov.br. 
maior perigo com relação ao uso excessivo de substâncias químicas e às depressões, entre outros tipos de problemas, nesse caso, um aspecto que necessita de mais pesquisas.

Desenvolver o trabalho em equipe é a base para a eficácia do resultado das ações da Atenção Básica (OLIVEIRA; POMPEU, 2015, p. 4). Além desse requisito, os profissionais de ACS possuem um papel de educador e de mobilizador da comunidade.E, para melhores resultados em situações de desastres, recomenda-se a existência de ações integradas entre a secretaria de saúde, a defesa civil e a vigilância sanitária, assim como as contribuições desses órgãos para o reconhecimento do saber local e para o diagnóstico das vulnerabilidades, e, nesse caso,novamente ganham destaque os Agentes Comunitários de Saúde (ROCHA, 2015, p. 54 e 157).

A Organização das Nações Unidas (ONU) designou 1994 como o Ano Internacional da Família e, também, no mesmo ano, no Brasil, foi criada, pelo Ministério da Saúde, a Estratégia de Saúde da Família (ESF), seguindo as diretrizes do Sistema Único de Saúde (SUS) e tomando a família como eixo estrutural em relação aos fatores condicionantes e determinantes do processo saúde-doença da população (MARQUI et al., 2010).

Assim,na Atenção Básica, o foco na família encontra seu refinamento na Saúde da Família (UFSP; UNA-SUS, 2016, p. 57), cujo núcleo é profundamente afetado em desastres, seja com a morte de entes queridos, seja com a perda de casas e, até mesmo, do território.

A equipe básica da ESF é composta de um médico generalista, um enfermeiro, um auxiliar de enfermagem e vários agentes comunitários de saúde. Essa equipe pode contar também com profissionais de saúde bucal. Além desses trabalhadores, também compõem a equipe recepcionistas e funcionários de limpeza. Outros servidores, que não os citados anteriormente, participaram das oficinas vindos de outros segmentos da Atenção Básica, pois a Secretaria de Saúde do Município entende que quanto mais servidores da saúde fizerem parte dos treinamentos, mais a secretaria estará preparada para lidar com desastres.

As oficinas fizeram parte do projeto de educação continuada para situações de desastres, realizado com os profissionais da Atenção Básica do município de Petrópolis em parceria com a Rede de Cuidados-RJ (ONG).

Para Candau (1999), oficina é uma metodologia de trabalho de grupo que tem como objetivo a superação da separação existente entre teoria e prática, além de ser uma possibilidade de vivência em direitos humanos. É utilizada para a formação e a construção coletiva de conhecimento, por meio de momentos de reflexão, interação e de trocas de saberes em uma horizontalidade na composição do saber inacabado, possui o diálogo e a troca de experiências como elementos condutores.

O uso da metodologia de oficinas é amplamente utilizado na Atenção Básica e, dentro dela, no programa de Estratégia de Saúde da Família (ESF). É uma técnica que ressoa com os princípios da ESF: humanização, integralidade, intersetorialidade, saúde como um direito, identificação e intervenção dos fatores de risco. Como já citado, a ESF conta com uma equipe multiprofissional, que, pela proximidade com o território, tem a capacidadede reconhecer as reais necessidades de saúde da comunidade. 
Os profissionais da Atenção Básica que participaram dos encontros foram: agentes comunitários de saúde, dentistas, médicos, profissionais de educação física, enfermeiros, auxiliares de saúde bucal, técnicos e auxiliares de enfermagem, além de recepcionistas. No total, cerca de 300 profissionais da rede de saúde das Unidades da Estratégia Saúde da Família passaram por oficinas presenciais durante o ano de 2018, nas quais foram utilizadas aulas expositivas, recursos audiovisuais e atividades da obra que serviu de embasamento para as reuniões.

Com grupos de 30/40 pessoas, as oficinas foram mensais e mesclaram as profissões e as diversas regiões das Unidades de Saúde. Não houve necessidade de identificação nas respostas, ou seja, todos tiveram suas identidades preservadas. Considerando que, para a construção das memórias coletivas, ocorre a elaboração do que é significativo para o grupo em questão (JEDLOWSKI, 2000), foi privilegiada a escuta dos profissionais da atenção básica sobre suas vivências e percepções em situações de desastres socioambientais.

As oficinas se desenvolveram a partir da perspectiva da Psicologia HumanistaExistencial, utilizando-se os referenciais teóricos da Abordagem Centrada na Pessoa, uma representante da terceira força em Psicologia (GONDRA, 1981; ROGERS; ROSEMBERG,1977).

A obra Inundações e Cuidado Integral: guia para discussões técnicas e comunitárias (2018) embasou as oficinas. Esse guia oferece sugestões de exercícios que podem ser utilizados por comunidades, grupos profissionais, gestores, associações, entre outros, com a característica de facilitar o diálogo e semear a possibilidade de construção conjunta para situações de desastres. Esse instrumento foi utilizado com o fim de ser "disparador" para o exercício sobre vivências em desastres.

\section{Resultados e discussões}

Para trabalhar os resultados, foi realizada uma primeira leitura a partir do material produzido nas oficinas, tendo como referência uma abordagem compreensiva do vivenciado por profissionais participantes. Posteriormente, teve lugar a análise de conteúdo (MINAYO, 2014, p. 299-318) com a sistematização dos dados qualitativos e quantitativos. O quadro de análise não foi determinado previamente.

Para a realização das oficinas, foram selecionadas quatro atividades de Inundações e Cuidado Integral-Guia para discussões técnicas e comunitárias (VALENCIO; IBRAHIM; GONÇALVES, 2018), todas elas com função mobilizadora para o trabalho a ser realizado. As categorias foram desenvolvidas a partir da análise de conteúdo do resultado dos encontros.

A seguir, serão apresentados os resultados de cada uma delas - Atividade I, Atividade II, Atividade III e Atividade IV, acompanhados de suas respectivas discussões.

\subsection{Resultado da atividade I}

Nessa ação,foram escolhidas cinco perguntas, tendo como base o Capítulo 2 do Guia - Alagamentos, enchentes e inundações, especificamente a página 20: 
1. Você já viu algumas dessas situações?

2. Como isso atrapalhou a sua vida?

3. O que você acha que pode ser feito para melhorar essas situações?

4. Quem é responsável por essas situações?

5. Quem paga “o pato"(expressão usada informalmente para designar quem é penalizado e sofre as consequências de uma determinada situação)?

Essa atividade originou a categoria (1) Vivência/Experiência.

Essa categoria contempla o fato de que a maioria dos participantes já vivenciou situações de desastres como afetado, profissional ou ambos os casos. As repercussões em suas vidas estiveram e estão presentes, tanto de forma subjetiva quanto objetiva. O exercício trouxe, para alguns, memórias de desastres anteriores, vividos ao longo de sua vida. A sobrecarga de trabalho, o abandono do poder público e a mobilização com a dor do outro também marcaram essa categoria. Os resultados ressoam com o sofrimento e o desgaste dos profissionais que atuam no serviço público com relações de ajuda (FASSIN, 2006).

E, ainda, quatro subcategorias foram desenvolvidas: (i) Memórias de vivências em desastres: consequências multidimensionais; (ii) Aprendizagem para ação: prevenção e escuta qualificada, rever políticas públicas e ações governamentais; (iii) Responsabilidade sobre os desastres: esferas governamentais (municipal, estadual, federal), governos e população, ou só a população; e (iv) Quem paga o "pato"?

Sobre o que pode ser feito para melhorar, houve sugestão de diversas ações de prevenção com escuta qualificada, surgiram criticas e foram propostas várias ideias para ações governamentais e para políticas públicas. Quanto à responsabilidade sobre os desastres, as esferas governamentais, municipal, estadual e federal, são apontadas, assim como a responsabilidade dividida entre governo e população, ou só a população. "Quem paga o 'pato'?": segundo os profissionais, quem paga são todos, desde os mais ricos até os mais vulneráveis sofrem as consequências dos desastres.

Seguem alguns testemunhos:

1. "Foram momentos difíceis e traumatizantes".

2. "Triste, pois não podia ajudar o suficiente".

3. "Desenvolvi, por cerca de dois anos, hipertensão".

4. "Tive que sair de casa de madrugada para ajudar pessoas, deixando os meus sem cuidados".

5. “[...] perdemos familiares na enchente de 1988, eu tinha oito anos de idade, foi muito triste para a minha família”.

6. "Ver que nada foi feito para resolver o problema, foi um caos e não houve apoio de nenhum órgão, apenas da corrente do bem”.

7. "Da segunda vez, minha casa (que comprei) foi interditada pela defesa Civil e vivo até hoje de aluguel social do município. Mudou radicalmente minha vida".

A história dos petropolitanos é a de quem conviveu e convive com desastres. Como já foi dito, nos encontros, emergiram as memórias dos participantes com relação aos desastres vivenciados, seja como diretamente afetado, seja quando atuaram como 
profissionais, ou como ambos. Exercitaram a construção da memória coletiva: “[...] conjunto de representações do passado que um grupo produz, elabora e transmite através da interação entre seus membros" (JEDLOWSKI, 2000, p. 125). Assim, nas oficinas, os profissionais puderam apresentar suas vivências pessoais e descobrir em conjunto as memórias significativas para o grupo, memórias construídas nas relações e do presente para o passado (HALBWACHS, 2003), tendo como base as histórias vividas:

Não basta reconstituir pedaço a pedaço a imagem de um acontecimento passado para obter uma lembrança. É preciso que esta reconstrução funcione a partir de dados ou de noções comuns que estejam em nosso espírito e também no dos outros, porque elas estão sempre passando destes para aqueles e vice-versa[...]. (HALBWACHS, 2003, p 39)

\subsection{Discussão da Atividade I}

Acredita-se que o trabalho com memórias pode ser um valioso instrumento para auxiliar nas ações de reconstrução em desastres:trabalhar o passado a partir do presente e construir possibilidades de projetos futuros (JEDLOWSKI, 2000, p. 128). Uma característica dual da memória, que, segundo Appadurai em entrevista concedida a Ferreira (2009, p. 133-140), surge é: enquanto processa o dano, a memória facilita sua reparação, exercendo um papel terapêutico.

Assim, nas oficinas, as memórias foram aquelas que levaram à dor e ao abandono. A situação dos desabrigados com relação à inexistência de solução digna para a falta de moradia foi lembrada durante as oficinas, sendo que alguns participantes vivenciaram ou vivenciam este lugar. É importante lembrar que o desalojado de hoje pode se tornar amanhã um desabrigado. O estudo conduzido por Valencio, Marchezini e Siena (2008, p. 5) aponta a dinâmica: "Assim, os que entram nas estatísticas iniciais de pós-desastre como desalojados podem tornar-se desabrigados no momento seguinte, pois a situação de pobreza não constrói alternativas sólidas para mitigar o sofrimento social."

A insegurança e a descrença acompanham os moradores, fazendo parte de um conjunto de sinais que levam os cidadãos para um lugar de fragilidade.

\subsection{Resultado da atividade II}

Nessa etapa,a reflexão foi gerada com as questões do item 3.1 Dimensões da vida privada e da vida pública, especificamente a página 25 do Guia:

1. Quem, em caso de emergência, deve ser acudido primeiro?

2. Como minorar o sofrimento enquanto o socorro não chega?

3. Como promover a recuperação social do lugar?

A análise desta etapa originou a categoria (2): Ação e Recuperação Social. A maioria dos participantes considerou que idosos, crianças, gestantes e pessoas com 
necessidades especiais devem ter prioridade no socorro. Enquanto esperam pela chegada de ajuda especializada, o acolhimento ganhou destaque como instrumento a ser utilizado por aqueles que chegam primeiro, com indicação de medidas de segurança, calma e orientações gerais. Para a recuperação social, as sugestões estão nas categorias de mobilização comunitária e social, políticas públicas eficientes, parcerias entre comunidades e poder público e resgate emocional.

Os resultados desta reflexão encontram respaldo nos direitos priorizados na Carta Humanitária - Manual Esfera (ASOCIACIÓN ESFERA, 2018): de viver com dignidade, de receber assistência humanitária e de ter proteção e segurança em situação de desastres.

Duas subcategorias foram elencadas (2.a) Primeiras horas: contar com quem está ao lado e (2.b) Recuperação (mobilização comunitária e social, resgate emocional, políticas públicas eficientes, parcerias entre comunidade e poder público, destaque para ações psicológicas e resgate emocional).

Algumas falas dos participantes para ilustrar:

- $\quad$ "Com a ajuda da população local que não foi atingida, apoio emocional e resgates necessários”.

- "Oferecer local seguro e confortável/ oferecer algo (toalhas, bebida quente, roupas limpas, alimentos, descanso)".

- "Para refazer o equilíbrio, precisamos que alguém nos fortaleça para fortalecer os outros".

- "Promover o resgate emocional com apoio psicológico com suporte às demandas dos sobreviventes".

- "Oficinas de acolhimento e escuta qualificada".

\subsection{Discussão da atividade II}

A discussão movida pelos participantes girou em torno do local onde aconteceu o desastre, considerando segurança e acolhimento como prioridade: quem atender primeiro, como realizar a recuperação social, como prover suporte psicossocial. Eles entenderam também que, no primeiro momento, contam com quem está ao lado. É importante o reconhecimento de seu território de origem, isso também contribui para o autoconhecimento e para suas relações interpessoais, assim como favorece a tomada de consciência dos diversos níveis (social, político, econômico, cultural) que compõem o viver no dia a dia. Mesmo considerando que, por meio da globalização, se chegou à homogeneização dos diferentes locais onde se vive, o que acabou tornando o lugar irrelevante. Você pode comer o mesmo prato em qualquer lugar do mundo. Pode dormir na mesma cama, no mesmo quarto, do mesmo hotel. Computadores e carros iguais estão disponíveis em qualquer lugar. A TV é a mesma!

Sendo privadas de seus espaços, as famílias têm seu sustento financeiro comprometido e, também, circunstâncias que produzem reflexos no senso de SER, de identidade. "Na Grécia pré-cristã, o lugar específico, real, era intimamente ligado à essência de alguém". Ousia, a palavra grega para "propriedade, terra", passou a significar "ser" 
(WOOD, 2008, p. 383). David Orr (2008 apudWOOD, 2010), professor de estudos do ambiente, dá apoio a essa ideia: "Conhecimento de um lugar - onde você está e de onde veio - está entranhado com o conhecimento de quem você é. Paisagens naturais, em outras palavras, moldam paisagens mentais. Para o potencial humano o que é mais essencial do que saber quem você é?” (ORR, 2008apud WOOD, 2010, p. 383)

\subsection{Resultados da atividade III}

A prática foi mobilizada a partir de ponderações do Guia sobre a parte $3.3 \mathrm{~A}$ Dimensão Psíquica, especificamente a página 45:

1. Como se sente em relação aos desastres?

2. Sente-se apoiado(a) comunitariamente se acontecer um desastre?

3. Que tipo de auxílio espera dos órgãos governamentais em caso de desastre?

4. O que você aponta como mais difícil num desastre?

Originou a categoria (3) - Subjetividade - e mostrou os sentimentos que fazem parte do repertório dos participantes diante de desastres. Eles se mostraram divididos entre se sentirem ou não apoiados comunitariamente em desastres. E alguns não se pronunciaram. Sobre a ajuda esperada dos órgãos governamentais, as respostas apontaram para projetos que considerem o cuidado integral, evidenciando a necessidade de contemplar as múltiplas dimensões que envolvem desastres. Sinalizaram a necessidade de cuidado psicossocial e médico, com destaque para apoio psicológico, tanto nos abrigos quanto em fase posterior. Do poder público esperam apoio financeiro, resposta e apoio imediato, abrigos estruturados com atendimento das necessidades básicas, áreas para moradia, reconstrução do local com segurança, agilidade nas respostas e ações preventivas. Há os que estão sem esperança e nada mais esperam - descrédito; e há os que preferem não falar sobre o assunto.

Eles apontaram também a falta de apoio dos governos, nas três esferas (governo municipal, governo estadual e governo federal), além da corrupção e da falta de ética. O que foi considerado mais difícil são as perdas objetivas e subjetivas, necessitando de apoio psicológico inexistente, além disso, eles apontaram a ineficiência das políticas públicas, assim como os entraves na fase de reconstrução; o sentimento de impotência, como mostram as falas:

- “Triste e apavorado, porque não vem ajuda de lugar nenhum, somente de quem mora no mesmo local”.

- "Sinto que poderiam ser evitados (os desastres), se a administração pública fizesse o seu papel”.

- $\quad$ "Que cumpram seu papel com ética, dignidade e sem roubo dos recursos enviados para os necessitados".

- "A chegada do socorro [...] Existe demora e desorganização. Todos parecem baratas tontas".

- "Que a real necessidade seja atendida e não os interesses políticos ou de quem tem algum poder". 


\subsection{Discussão da atividade III}

O capitalismo predatório e as políticas que privilegiam interesses privados e o sistema de circulação acabam por descaracterizar bairros, expulsando moradores denominados de favelados, encortiçados, sem teto, desalojados e desabrigados, num nomadismo sem direito às raízes (VERAS, 2014, p. 35). Martins (1997apud VERAS, 2014) aponta que políticas econômicas atuais, neoliberais, acabam por provocar não políticas de exclusão, e, sim, políticas de inclusão precária e marginal, ou seja, incluem pessoas nos processos econômicos, na circulação e na produção de bens e serviços estritamente em termos daquilo que é racionalmente conveniente e necessário para a mais eficiente e barata reprodução do capital.

A supressão de direitos caminha na direção de um sentido mais profundo da exclusão que é estar ligado ao desejo dos brasileiros burgueses de mostrar que os dominados são diferentes, segregando-os, como ressaltado por Oliveira (2014apudVERAS, 2014, p. 45):

O apartheid se caracteriza pela criação de um campo semântico em que os significados dos direitos e conquistas civilizatórios, plasmados em direitos sociais, trabalhistas, civis e políticos são transformados em fatores causais da miséria, pobreza e exclusão, em obstáculo ao desenvolvimento econômico e, mais, são transformados em ausência de cidadania.

\subsection{Resultados da atividade IV}

Na última etapa, duas questões foram facilitadoras do trabalho, retiradas do Guia no capítulo 3.5 A integralidade do ser-no-mundo em meio a essas adversidades, especificamente a página 52 :

1. As ações governamentais atingem a integralidade humana durante as situações de desastres?

2. Durante os desastres,quais dimensões humanas se mostram mais vulneráveis?

A categoria desenvolvida foi (4) Ações Governamentais e Vulnerabilidade. Foi possível perceber que a compreensão desta atividade ficou comprometida: por ser uma proposta a qual eles não estão habituados, ou por ter ficado por último, prejudicada pela proximidade do final do horário e/ou tempestade ao entardecer. Os participantes destacaram a dimensão psicológica como a mais vulnerável. Também reconheceram a vulnerabilidade nas dimensões social, física, financeira, espiritual e cultural.

Trechos de colocações dos participantes trazem vida para esta categoria:

- " “...]a integralidade é a melhor forma de trabalhar, mas ela demora a acontecer".

- “[...] nem sempre é possível ofertar tudo aquilo que as famílias necessitam”. 
- "As ações governamentais mais efetivas garantiriam a diminuição de situações de desastres e/ou seus agravos".

- “[...] Vai depender do psíquico de cada indivíduo, que vai ter uma reação a tudo que está vivenciando, afinal é algo novo e cruel”.

- “[...] em 2013 eu tinha três anos que morava em Petrópolis e um ano na prefeitura. Fiquei apavorada com o alvoroço das pessoas e o desespero. Em minha comunidade morreram cerca de 10 pessoas, inclusive um membro da defesa civil. [...] Todos ficam muito apavorados, alguns parecem até pior do que quem vivenciou a situação".

\subsection{Discussão da atividade IV}

Foi possível constatar, nos grupos de trabalho, a preocupação no sentido de que os poucos recursos disponíveis sejam utilizados, a fim de viabilizar a sobrevivência dos mais afetados. A maioria dos participantes destacou que as ações governamentais não atingem a integralidade humana em desastres e que as diversas dimensões sofrem danos (física, psicológica, social, econômica).

Nesse ponto, é necessário contar com as sugestões de Poland (2008,p. 7), quando ele propõe ferramentas para uma nova era. Os desafios colocados pelas "forças tectônicas" convergentes em função do crescimento populacional - diminuição das reservas de energia, degradação ambiental, mudanças climáticas, e a distância crescente entre ricos e pobres- necessitam de servidores sociais e de saúde que olhem além de suas funções tradicionais e fronteiras disciplinares (HOMER-DIXON, 2006 apud POLAND, 2008).

São cinco as propostas colocadas por Poland (2008):

1. Começar por onde as pessoas estão- (respeitar e escutar as histórias de vida, compreendendo todas os formatos de comunicação, incluindo as artes).

2. Considerar a experiência e cultura regional.

3. Aprofundar-se na análise social, contribuindo para as narrativas individuais e comunitárias, promovendo um diálogo crítico com as práticas organizacionais.

4. Acentuar características positivas e não prender-se a estereótipos e incapacidades.

5. Contribuir para construção de resiliência individual e coletiva.

Mais do que preparar profissionais e populações para o enfrentamento de emergências e desastres, seja por meio de equipamentos que facilitam o despertar para o perigo, como as sirenes; seja criando os chamados pontos de apoio (locais mais protegidos que as moradias em risco); seja levando informações e capacitando pessoas para atuarem nessas situações, acredita-se que é necessário que haja uma nova compreensão, mais ampla, de que esses acontecimentos apontem para desequilíbrios capazes de comprometer a vida no planeta, levando à extinção milhares de espécies que formam a teia da vida e sustentam a continuidade das gerações. As mudanças 
essenciais não serão obra dessa ou daquela categoria, ou campo de conhecimento, mas da união de todos, pois somos uma parcela que compõe o todo da terra. É necessário compreender que o homem não está separado, ele faz parte da natureza, apesar das ilusões que o avanço científico cria, incentivando o mito da separatividade e causando o encapsulamento das pessoas que passam a sofrer de isolamento, solidão e competição. Felizmente, nas fronteiras da ciência, nas últimas décadas, alvissareiras constatações apontam a interdependência, a não separatividade e a necessidade de reconhecer como "real" as relações e não as "coisas em si". Estamos caminhando, oxalá tenhamos tempo de iniciar esse processo de mudança de consciência.

Em consonância com o trabalho de Silva, Campos e Bandeira (2020), destaca-se que a impossibilidade de reproduzir de forma experimental as situações de desastres faz com que fatos históricos necessitem de análise cuidadosa, com o objetivo de melhorar as respostas futuras das equipes de trabalho, assim como a dos gestores. Oficinas, exercícios e simulações de desastres fazem parte de uma estratégia contínua de desenvolvimento e de preparação dos profissionais.

\section{Conclusão}

Os resultados das oficinas demonstraram que os profissionais da Atenção Básica na Estratégia Saúde da Família, no Município de Petrópolis, necessitam de apoio emocional, aprendizagem, confiabilidade nos órgãos públicos e desenvolvimento de habilidades e competências para que possam lidar com os diversos aspectos que envolvem as emergências e os desastres.

Pode-se afirmar também que bons resultados podem ser esperados na medida em que os trabalhos desenvolvidos possuam um caráter interdisciplinar e intersetorial, o que exige a criação de relações simétricas entre os diferentes cidadãos e os órgãos envolvidos. Porém, os participantes evidenciaram que suas solicitações não são atendidas e não se sentem ouvidos. Entendem que, pela responsabilidade e pelas características de suas atribuições, deveriam ter mais autonomia, assim como o reconhecimento de seus conhecimentos sobre as necessidades e os riscos da comunidade.

Além do entendimento da situação, se faz necessária a compreensão da subjetividade humana implicada em sua multidimensionalidade ao longo das diversas transformações que acontecem no concreto geográfico, nos referenciais emocionais, na noção de tempo e na lógica da necessidade de superação para reconstrução da própria vida. Nesse sentido, destaca-se que alguns participantes foram sobreviventes de desastres que aconteceram quando eram crianças. Uma lembrança presente.

Os participantes colocaram em evidência o sofrimento social em desastres, a importância de se desenvolver instrumentos como a prática do acolhimento, que é preconizada como atitude para o início do cuidado integral. A solidariedade, a prevenção e a intersetorialidade são destacadas como formas de atuação que hoje inexistem. Os participantes ressaltam a falta de compromisso dos órgãos públicos, o que resulta em consequências para as comunidades, sendo sempre a população a grande prejudicada. Para a recuperação social, eles apontam a necessidade de união entre as pessoas. 
A dimensão emocional é considerada a mais vulnerável nessas situações, tanto por parte dos sobreviventes quanto dos profissionais.

A constatação de alguns autores é a de que essas situações de desastres e emergências envolvem grande complexidade, indo desde a compreensão de processos históricos até as atitudes que permeiam as ações no trabalho de campo, exigindo uma ampliação do olhar no sentido de criar novas ferramentas capazes de transformar o estado atual da compreensão do que é um desastre e, principalmente, qual é o lugar do homem, intencionalmente colocado como o cerne de um pensamento sistêmico em que a interdependência passe a ser gradiente básico no entendimento para a construção de políticas públicas capazes de garantir a produção de cidadania.

Considera-se que os resultados são norteadores para a atualização das políticas públicas em desastres e contribuem para a construção do cuidado integral. 


\section{Referências}

ASOCIACIÓN ESFERA. Manual Esfera: Carta Humanitaria y normas mínimas para la respuesta humanitaria, cuarta edición, Ginebra, Suiza, 2018. Disponível em: www. spherestandards.org/handbook. Acesso em:2 jun. 2020.

BARDIN, L. Análise de Conteúdo. São Paulo: Edições 70, 2016.

BRASIL. Ministério da Saúde. Portaria n.1.886, de 18 de dezembro de 1997. Aprova as normas e diretrizes do Programa de Agente Comunitário e do Programa de Saúde da Família e dá outras providênicias. Diário Oficial da União, Brasília, DF,22 de dezembro de 1997. Disponível em: https://www.legisweb.com.br/legislacao/?id=181515. Acesso em:2 jun. 2020.

BRASIL. Câmara dos Deputados. 1999. Disponível em: https://www2.camara.leg. br/legin/fed/decret/1999/decreto-3189-4-outubro-1999-369118-publicacaooriginal-1-pe.htm. Acesso em:3 out. 2019.

BRASIL. Ministério do Meio Ambiente. Instituto Brasileiro do Meio Ambiente e dos Recursos Naturais Renováveis. Plano de Manejo Área de Proteção Ambiental da Região Serrana de Petrópolis, 2007. p 489. Disponível em: http://www.icmbio.gov. br/portal/images/stories/imgs-unidades-coservacao/apa_petropolis.pdf. Acesso em:3 out. 2019.

BRASIL. Ministério do Desenvolvimento Regional. Secretaria Nacional de Defesa Civil. Planejamento Estratégico Integrado para as Ações de Prevenção e Preparação contra Desastres Naturais nos Municípios da Região Serrana. Rio de Janeiro: SNDC, 2011. Disponível em: https://www.mdr.gov.br/protecao-e-defesa-civil/publicacoes. Acesso em:3 out. 2019.

BRASIL. Ministério do Desenvolvimento Regional. Secretaria Nacional de Defesa Civil. Anuário Brasileiro de Desastres Naturais 2011. Centro Nacional de Gerenciamento de Riscos e Desastres. CENAD, Brasília, 2012a. p 82. Disponível em: https://www.mdr. gov.br/protecao-e-defesa-civil/publicacoes. Acesso em:10 jul. 2013.

BRASIL. Secretaria Nacional de Proteção e Defesa Civil (SNPDC). Política Nacional de Proteção e Defesa Civil. Lei 12.608. 2012b. Disponível em: http://www.planalto. gov.br/ccivil_03/_Ato2011-2014/2012/Lei/L12608.htm. Acesso em: 2 out. 2012.

BRASIL. Força Tarefa de Apoio Técnico e Emergência. 2012c. Disponível em: https:// pt.wikipedia.org/wiki/For\%C3\%A7a_Nacional_de_Apoio_T\%C3\%A9cnico_de_ Emerg\%C3\%AAncia. Acesso em:2 out. 2014. 
BRASIL. Ministério do Desenvolvimento Regional. Secretaria Nacional de Proteção e Defesa Civil. Centro Nacional de Gerenciamento de Riscos e Desastres. Anuário Brasileiro de Desastres Naturais 2013. Brasília: CENAD, 2014. p. 75. Disponível em: https://www.mdr.gov.br/protecao-e-defesa-civil/publicacoes. Acesso em:2 jan. 2014.

BRASIL. Ministério do Desenvolvomento Regional. Secretaria Nacional de Defesa Civil. Anuário Brasileiro de Desastres Naturais 2012. Centro Nacional de Gerenciamento de Riscos e Desastres. Brasília: CENAD, 2013. p 88. Disponível em: https://www.mdr. gov.br/protecao-e-defesa-civil/publicacoes. Acesso em:2 jan. 2013.

BRASIL. Ministério do Desenvolvomento Regional. Secretaria Nacional de Proteção e Defesa Civil. Brasília: 2012b. Disponível em: http://www.planalto.gov.br/ccivil_03/_ato2011-2014/2012/lei/112608.htm\#: :text=1\%C2\%BA\%20Esta\%20Lei\%20 institui\%20a,desastres\%20e\%20d\%C3\%A1\%20outras\%20provid\%C3\%AAncias.

BRASIL. Centro Nacional de Monitoramento e Alerta de Desastres Naturais (CEMADEN) [2019a]. Disponível em: http://www.cemaden.gov.br/. Acesso em:3 jul. 2020.

BRASIL. Ministério da Saúde. Princípios do SUS e Estratégia Saúde da Família. [2019b]. Disponível em: https://www.saude.gov.br/acoes-e-programas/saude-da-família. Acesso em: 3 jul. 2020.

BRASIL. Biblioteca Virtual em Saúde. Atenção primária em saúde. [2019c]. Disponível em: https://aps.bvs.br/aps/quando-foi-iniciada-a-estrategia-de-saude-da-familia-no-brasil/. Acesso em:2 jul. 2020.

BRASIL ESCOLA. [2019]. Disponível em: https://brasilescola.uol.com.br/o-que-e/ historia/o-que-e-sesmaria.htm. Acesso em:2 jul. 2020.

CANDAU, V. Oficinas Aprendendo e Ensinando Direitos Humanos. Educação em Direitos Humanos: uma Proposta de Trabalho. 1999. Disponível em: http://www. dhnet.org.br/direitos/militantes/veracandau/candau_edh_proposta_trabalho.pdf. Acesso em:2 ago. 2020.

FASSIN, D. Souffrir par le social, gouverner par l'écoute:une configuration sémantique de l'action publique. Politix, [s.l.], v. 1, n. 73,p. 137-157, 2006. Disponível em: https:// www.cairn.info/revue-politix-2006-1-page-137,htm. Acesso em: 7 nov. 2017.

FERREIRA, T. Nome. Entrevista Arjun Appadurai. Veriati - Repositório Institucional da Universidade Católica Portuguesa Sede (Lisboa), Faculdade de Ciências Humanas Centro de Estudos de Comunicação e Cultura (CECC). Revista Comunicação \& Cultura, [s.l.], n. 7, p. 133-140, 2009. Dispónível em: http://repositorio.ucp.pt/handle/10400. Acesso em: 2 mar. 2017. 
GONDRA, J. M. La psicoterapia de Carl R. Rogers. Bilbao: Editorial Espanola Desclée de Brouwer, 1981. p 372.

GUERRA, A. J. T.; CUNHA, S. B. Impactos Ambientais Urbanos no Brasil. 4. ed. Rio de Janeiro: Bertrand Brasil, 2006. p. 416.

HALBWACHS, M.A. A memória coletiva. São Paulo: Centauro,2003.p.222.

JEDLOWSKI, P. La sociologia y la memoria colectiva. In: ROSA, A.;BELLELLI, G.;BAKHURST, D. (ed.). Memória colectiva y identidad nacional. Biblioteca Nueva, Madrid, 2000. p. 123-134.

MARQUI, A.B.T.et al. Caracterização das equipes da Saúde da Família e de seu processo de trabalho. Revista da Escola de Enfermagem da USP, São Paulo, v.44, n.4, p. 956-961, 2010. Disponível em: https://www.scielo.br/scielo.php?script=sci_arttext\&pid=S0080-62342010000400014\#: :text=A\%20equipe\%20b\%C3\%A1sica\%20 ou\%20nuclear,mental\%20e\%20reabil. Acesso em: 6jul. 2020.

MINAYO, M. C. S. Desafio do Conhecimento: pesquisa qualitativa em saúde.14. ed. São Paulo: Hucitec, 2014. p 407.

OLIVEIRA, W.A.;POMPEU, E.L.T. O papel da atenção básica nos desastres de origem natural no Brasil. Revista de Saúde da Faciplac, Brasília, DF, v. 2, n. 1, p. 51-65, jan.-dez. 2015. Disponível em: http://revista.faciplac.edu.br/index.php/RSF/article/ view/103/59. Acesso em: $1^{\circ}$ nov. 2019.

OPAS - ORGANIZAÇÃO PAN-AMERICANA DA SAÚDE. La Salud Pública en las Américas: Nuevos Conceptos, Análisis Del Desempeño, Bases para la Acción. Washington DC: OPAS, 2002.

OPAS - ORGANIZAÇÃO PAN-AMERICANA DA SAÚDE. Apoyo psicosocial en emergencias y desastres: Guía para equipos de respuesta. Panamá: OPAS, 2010a.

OPAS - ORGANIZAÇÃO PAN-AMERICANA DA SAÚDE. Evaluación de daños y análisis de necesidades de salud en situaciones de desastre (EDAN): Guía para equipos de respuesta. Panamá: OPAS, 2010b. Disponível em: https:// www.paho.org/disasters/index.php? option $=$ com_docman\&view=download \& category_slug=books\&alias $=1086$-evaluacion-de-danos- $y$-analisis-de-necesidades-de-salud-en-situaciones-de-desastre\&Itemid=1179\&lang=es. Acesso em:2 jul. 2020.

OPAS - ORGANIZAÇÃO PAN-AMERICANA DA SAÚDE; MS - MINISTÉRIO DA SAÚDE. Desastres Naturais e Saúde no Brasil: Série Desenvolvimento Sustentável e Saúde 2. ed. Brasília, DF: OPAS; MS, 2014. 
OPAS - ORGANIZAÇÃO PAN-AMERICANA DA SAÚDE; OMS - ORGANIZAÇÃO MUNDIAL DA SAÚDE. Agenda de Saúde Sustentável para as Américas: um chamado à ação para a saúde e o bem-estar na região. 29ª Conferência Sanitária Pan-Americana e 69a Sessão do Comitê Regional da OMS para as Américas. Washington: OPAS. OMS, 2017. Disponível em: https://iris.paho.org/bitstream/handle/10665.2/49172/ CSP296por.pdf? sequence=1\&isAllowed=y. Acesso em: 6 jul. 2020.

PETRÓPOLIS. Prefeitura Municipal de Petrópolis. Plano Municipal de Saneamento Básico de Petrópolis. 2014. Disponível em: http://www.petropolis.rj.gov.br/e-gov/spe/ home_ftp/secplan/PMSB.pdf. Acesso em: 2 out. 2019.

PETRÓPOLIS. Diário Oficial do Município de Petrópolis. Política Municipal dos Princípios da Proteção e Defesa Civil e a Educação Ambiental. Lei n. 7.654. de 3 de maio de 2018.[2018a].Disponível em: http://www.petropolis.rj.gov.br/pmp/index. $\mathrm{php/servicos-na-web/informacoes/diario-oficial/finish/227-maio/4239-5425-sexta-}$ -feira-4-de-maio-de-2018.html. Acesso em:2 jul. 2020.

PETRÓPOLIS. Prefeitura Municipal de Petrópolis. Defesa Civil nas escolas atinge 103 escolas públicas e 36 mil alunos. [2018b]. Disponível em: http://www.petropolis. rj.gov.br/pmp/index.php/imprensa/noticias/item/11807-defesa-civil-nas-escolas-atinge-103-escolas-p\%C3\%BAblicas-e-36-mil-alunos.html. Acesso em:2 jul. 2020.

PETRÓPOLIS. Secretaria Municipal de Saúde de Petrópolis. Plano de contingência de 2018. [2018c]. Disponível em: http://www.petropolis.rj.gov.br/pmp/phocadownload/programas_governo/plano_verao/plano\%20vero\%202018\%20-\%20inundaes $\% 20$ -\%20verso\%201.pdf Acesso em: 2 jun. 2019.

PETRÓPOLIS. Instituto Municipal de Cultura e Esportes. 2019. Disponível em: http:// www.petropolis.rj.gov.br/fct/index.php/petropolis/historia. Acesso em: $1^{\circ}$ nov. 2019.

POLAND, B. Humanismo e Salutogênese. In: CAVALCANTI JR., Francisco S.;SOUSA, André F. (org.). Humanismo de funcionamento pleno. Campinas, SP: Alínea, 2008. p. 5-9.

ROCHA, V.O papel do agente comunitário de saúde na prevenção de desastres naturais por deslizamento em comunidades da cidade do Rio de Janeiro-RJ, Brasil. 2015. 214p. Tese (Mestrado) - Programa de Pós-graduação em Saúde Pública da Escola Nacional de Saúde Pública Sérgio Arouca, Fundação Oswaldo Cruz, Rio de Janeiro, 2015.

ROGERS, C. R.;ROSEMBERG, R. A Pessoa como Centro. São Paulo: EPU, 1977. p.228.

SILVA, I.;CAMPOS, P.;BANDEIRA, R. Catástrofe de 20 de fevereiro de 2010 na Ilha da Madeira. O impacto nos interventores de saúde do serviço de urgência do hospital Dr. Hélio Mendonça. Territorium, [s.1.], v. 27, n. 1, p. 83-95, 2020. 
UFSP - UNIVERSIDADE FEDERAL DE SÃO PAULO; UNA-SUS - UNIVERSIDADE ABERTA DO SISTEMA ÚNICO DE SAÚDE. Gestão Local de Desastres Naturais para a Atenção Básica. São Paulo: UFSP; UNA-SUS, 2016. p. 122. Disponível em: http://www.unasus.unifesp.br.Acesso em: 2 jul. 2020.

VALENCIO, N.;IBRAHIM, S. Y.;GONÇALVES, J. C. (org.) Inundações e Cuidado Integral, Guia para discussões técnicas e comunitárias. São Carlos,SP: NEPED/ DCAm -UFSCar, Rede de Cuidados-RJ, 2018. p. 97. Disponível em: http://www.neped.ufscar.br/Arquivos/Cuidado_Integral_em_contexto_de_Inundacoes(versao_final_10MAR).pdf.Acesso em: 4jul. 2020.

VALENCIO, N.;MARCHEZINI, V.; SIENA, M. Após o desastre: abrigos temporários como loci de reafirmação dos afetados pelas chuvas. In: $26^{a}$ REUNIÃO BRASILEIRA DE ANTROPOLOGIA. Porto Seguro, Bahia, 2008. Anais [...].Porto Seguro, Bahia, Brasil, p. 1-25, 2008. Disponível em: http://www.abant.org.br/conteudo/ANAIS/CD_ Virtual_26_RBA/grupos_de_trabalho/trabalhos/GT\%2009/apos\%20o\%20desatre. pdf. Acesso em: 4 jul. 2020.

VERAS, M. P. B. Exclusão social - um problema brasileiro de 500 anos. Notas preliminares. In: SAWAIA, Bader et al. (org.). As artimanhas da Exclusão:análise psicossocial e ética da desigualdade social. 14. ed. Petrópolis, RJ: Vozes, 2014. p. 157. 